\title{
UV Irradiation Chlorine Dioxide Photocatalytic Oxidation of Simulated Fuchsine Wastewater by UV-Vis and Online FTIR Spectrophotometric Method
}

\author{
Laishun Shi, Xiaomei Wang, Na Li, Chunlei Huai, and Jie Liu \\ School of Chemistry and Chemical Engineering, Shandong University, South Campus, Jinan 250061, China \\ Correspondence should be addressed to Laishun Shi, shils888@yahoo.com.cn
}

Received 29 December 2011; Accepted 12 February 2012

Academic Editors: D. Patra and A. Szemik-Hojniak

Copyright () 2012 Laishun Shi et al. This is an open access article distributed under the Creative Commons Attribution License, which permits unrestricted use, distribution, and reproduction in any medium, provided the original work is properly cited.

\begin{abstract}
The photocatalyst $\mathrm{TiO}_{2} / \mathrm{SiO}_{2}$ was prepared and used for chlorine dioxide photocatalytic oxidation of simulated fuchsine wastewater under UV irradiation. The removal efficiency of fuchsine treated by photocatalytic oxidation process is higher than that of chemical oxidation process. By using UV-Vis and online FTIR analysis technique, the intermediates during the degradation process were obtained. The benzene ring in fuchsine was degraded into quinone and carboxylic acid and finally changed into carbon dioxide and water during the photocatalytic oxidation. The degradation reaction mechanism of fuchsine by UV irradiation chlorine dioxide photocatalytic oxidation was proposed based upon the experiment evidence.
\end{abstract}

\section{Introduction}

The effluents produced by some of our industries are harmful to the health and general well-being of man. When undesirable substances are present in liquid effluents, it can be disastrous as their presence pose severe threat to the immediate recipients. Wastewaters from various industries, factories, laboratories, and so forth are serious problems to the environment. Addressing these problems calls out for a tremendous amount of research to be conducted to identify robust new methods of purifying water at lower cost and with less energy, while at the same time minimizing the use of chemicals and impact on the environment [1].

In recent years, a variety of wastewater treatment techniques have been applied to degrade and remove refractory materials from wastewaters, including chemical oxidation [2], biodegradation [3], electrochemical oxidation degradation [4], catalytic oxidation degradation $[5,6]$, and so on. Also, to obtain a high removal efficiency of hazardous materials, a combination of physical and chemical techniques should also be employed [7]. These wastewater treatment processes generate very toxic wastewater, whose treatment is often difficult due to the presence of some non biodegradable species with complex structure. Hence there is considerable current interest in developing alternative and more costeffective methods to treat those refractory materials.

Advanced oxidation processes (AOPs) have been developed to meet the increasing need of an effective wastewater treatment. AOP generates powerful oxidizing-agent hydroxyl radicals which completely destroy major classes of organic pollutants at ambient conditions. The combination of UV irradiation with photocatalysts is one of such methods which have attracted considerable attention in recent years, due to its effectiveness in mineralization (i.e., conversion to inorganic species) of organic materials $[8,9]$. Heterogeneous photocatalysis through illumination of UV on a semiconductor surface such as $\mathrm{TiO}_{2}$ is an attractive advanced oxidation process [10]. Such a $\mathrm{UV}-\mathrm{TiO}_{2}$-based photocatalytic oxidation system exhibits some attractive characteristics. First, $\mathrm{TiO}_{2}$ is stable, insoluble, nontoxic, and environmentally acceptable by being fairly inert biologically and chemically. Second, $\mathrm{TiO}_{2}$ is inexpensive reusable. Third, the photocatalyst titanium dioxide $\left(\mathrm{TiO}_{2}\right)$ is a wide bandgap semiconductor $(3.2 \mathrm{eV})$, has high photoactivity, and is successfully used as a photocatalyst for the treatment of organic $[11,12]$ and dye pollutants [13-15].

The mechanism constituting heterogeneous photocatalytic oxidation processes has been discussed extensively in 
the literature $[16,17]$. Briefly, when a semiconductor such as $\mathrm{TiO}_{2}$ absorbs a photon of energy equal to or greater than its band gap width, an electron may be promoted from the valence band to the conduction band $\left(\mathrm{e}_{\mathrm{cb}}{ }^{-}\right)$leaving behind an electron vacancy or "hole" in the valence band $\left(\mathrm{h}_{\mathrm{vb}}{ }^{+}\right)$. If charge separation is maintained, the electron and hole may migrate to the catalyst surface where they participate in redox reactions with absorbed species. Specially, $\mathrm{h}_{\mathrm{vb}}{ }^{+}$ may react with surface-bound $\mathrm{H}_{2} \mathrm{O}$ or $\mathrm{OH}^{-}$to produce the hydroxyl radical, and $\mathrm{e}_{\mathrm{cb}}{ }^{-}$is picked up by oxygen to generate superoxide radical anion $\left(\mathrm{O}_{2}^{-\bullet}\right)$.

One practical problem in using $\mathrm{TiO}_{2}$ as a photocatalyst is the undesired electron-hole recombination, which, in the absence of proper electron acceptor or donor, is extremely efficient and represents the major energy-wasting step thus limiting the achievable quantum yield. One strategy to inhibit electron-hole pair recombination is to add other (irreversible) electron acceptors to the reaction. They could have several different effects, such as (1) to increase the number of trapped electrons and, consequently, avoid recombination, (2) to generate more radicals and other oxidizing species, (3) to increase the oxidation rate of intermediate compounds, and (4) to avoid problems caused by low oxygen concentration. In highly toxic wastewater where the degradation of organic pollutants is the major concern, the addition of electron acceptors to enhance the degradation rate may often be justified. Hydrogen peroxide used as electron acceptors was investigated in solar-lightinduced and $\mathrm{TiO}_{2}$-assisted degradation of textile dye reactive blue 4 [18]. The enhanced photodegradation efficiency in the presence of hydrogen peroxide may be either directly via conduction band electrons or indirectly via superoxide radical anion which produces hydroxyl radicals. The results indicate that the mineralization of the fragments is tremendously faster in the presence of hydrogen peroxide.

Taking the above-mentioned concept into account, the present study focused on the chlorine dioxide photocatalytic degradation of wastewater containing fuchsine by UV irradiation in the presence of titanium dioxide, where the strong oxidizer chlorine dioxide was also used as the electron acceptor. In our experiment, the photocatalyst $\mathrm{TiO}_{2} / \mathrm{SiO}_{2}$ was prepared. Moreover, in order to investigate the inherent essence of photocatalytic degradation mechanism, UV-Vis, FTIR, and online FTIR spectroscopy were also introduced. The intermediates were detected by online FTIR spectroscopy during the chlorine dioxide photocatalytic oxidation process. The degradation reaction mechanism of fuchsine by chlorine dioxide photocatalytic oxidation was proposed on the basis of the experiment evidences.

\section{Experimental}

2.1. Materials. The reagents used in the experiment were of analytical grade. The pure $\mathrm{ClO}_{2}$ aqueous solution was prepared by mixing a sulphuric acid aqueous solution and a sodium chlorite aqueous solution, where the sulphuric acid aqueous solution was added dropwise to the sodium chlorite aqueous solution. Subsequently, the gas obtained was absorbed by a sodium chlorite aqueous solution to remove the impurities, for example, chlorine. The remaining gas, chlorine dioxide, was absorbed by distilled water. Also, the $\mathrm{ClO}_{2}$ aqueous solution was stored in darkness. The $\mathrm{ClO}_{2}$ concentration was determined by the iodometric titration method before use. The concentration of fuchsine was $150 \mathrm{mg} / \mathrm{L}$.

The photocatalyst of $\mathrm{TiO}_{2} / \mathrm{SiO}_{2}$ was prepared according to the method of impregnation [19], immersing certain amounts of silica gel pretreated in Muffle furnace $4 \mathrm{~h}$ at $500^{\circ} \mathrm{C}$ into the mixture of butyl titanate and cyclohexane $\left.\left(V\left(\mathrm{Ti}(\mathrm{OBu})_{4}\right) / V\left(\mathrm{C}_{6} \mathrm{H}_{12}\right)\right)=4\right)$ for $15 \mathrm{~h}$, then evaporated cyclohexane at $40^{\circ} \mathrm{C}$ water bath and dried the catalyst at $120^{\circ} \mathrm{C}$ for $6 \mathrm{~h}$. Subsequently, the catalyst was calcined in Muffle furnace by three-step at air atmosphere: $200^{\circ} \mathrm{C}$ for $1 \mathrm{~h}, 350^{\circ} \mathrm{C}$ for $1 \mathrm{~h}, 450^{\circ} \mathrm{C}$ for $8 \mathrm{~h}$. The formatted active component $\mathrm{TiO}_{2}$ was loaded on the surface of silica gel, and the photocatalyst of $\mathrm{TiO}_{2} / \mathrm{SiO}_{2}$ was obtained.

2.2. Method. $100 \mathrm{~mL}$ of simulated wastewater containing fuchsine was added in a $250 \mathrm{~mL}$ three-necked flask, where the temperature was measured by thermometer. The $\mathrm{pH}$ value was adjusted by hydrochloric acid solution and sodium hydroxide to a certain value. The sample containing the appropriate concentration of $\mathrm{ClO}_{2}$ and photocatalyst was irradiated by means of UV lamps under magnetic stirring. Throughout the degradation experiment, the sample to be analyzed was withdrawn regularly from the flask and filtered to remove the photocatalyst. Then, the absorbance of the sample at $543 \mathrm{~nm}$ was obtained by UV-Vis spectrophotometer, and the removal efficiency was obtained according to the Lambert-Beer standard curve.

The removal efficiency $(E)$ of fuchsine was calculated as follows:

$$
E=\left[\frac{C_{0}-C_{i}}{C_{0}}\right] \times 100 \%,
$$

where $C_{0}$ is the initial concentration of wastewater containing fuchsine, $C_{i}$ is the concentration of sample treated under a certain condition.

2.3. UV-Vis Spectrophotometric Analysis. The simulated wastewater containing fuchsine, the effluent of chemical oxidation, and the effluent of photocatalytic oxidation were diluted 40 times before the analysis on TU-1800 PC UVVis spectrophotometer (Beijing Puxi Tongyong Instrument Company, Beijing, China). The UV-Vis spectrum of the water sample could be obtained in the range of $200 \mathrm{~nm}$ to $1000 \mathrm{~nm}$.

2.4. FTIR Analysis. FTIR spectra were recorded from 400 to $4000 \mathrm{~cm}^{-1}$ wavenumber range with averaging 32 scans at a resolution of $4 \mathrm{~cm}^{-1}$ on a Bruker Tensor-27 FTIR spectrophotometer. Both the effluent of chemical oxidation and the effluent of photocatalytic oxidation were evaporated in a water bath at $80^{\circ} \mathrm{C}$. Therefore, the solid samples were obtained and were used for the analysis of FTIR. 
2.5. Online FTIR Analysis during the Wastewater Treatment. The online FTIR analysis was performed on a ReactIR 4000 spectrophotometer (Mettler-Toledo AutoChem, Inc., USA). FTIR spectra were recorded from 400 to $4000 \mathrm{~cm}^{-1}$ wavenumber range at a resolution of $8 \mathrm{~cm}^{-1} .50 \mathrm{~mL}$ simulated wastewater containing fuchsine was added into a $250 \mathrm{~mL}$ flask, where the $\mathrm{pH}$ value was adjusted to 5.0 by hydrochloric acid solution. Then, chlorine dioxide solution, by maintaining the concentration of chlorine dioxide $6.14 \mathrm{mg} / \mathrm{L}$, and 0.5 grams of $\mathrm{TiO}_{2} / \mathrm{SiO}_{2}$ photocatalyst were added. In addition, using a magnetic stirrer allows for effective mixing in flask during the online FTIR measurement.

\section{Results and Discussion}

3.1. Lambert-Beer Standard Curve. The Lambert-Beer law is the linear relationship between absorbance and concentration of an absorber. The general Beer-Lambert law is usually written as

$$
A=\mathrm{K} b c,
$$

where $A$ is the measured absorbance, $\mathrm{K}$ is a wavelengthdependent absorption coefficient, $b$ is the path length, and $c$ is the sample concentration.

When the path length $b$ is a constant, $A$ is proportional to $c$. However, this theory is confirmed only in the limited range of the initial concentrations of fuchsine. Therefore the UV-Vis spectra of a series of dilutions from the solution of fuchsine were recorded at $543 \mathrm{~nm}$. Good linear fits between $A$ and $c$ according to Lambert-Beer law have been observed for fuchsine concentrations between 10 and $30 \mathrm{mg} / \mathrm{L}$. The linear equation is as follows:

$$
A=-0.0378+0.02204 c,
$$

where the linear correlation coefficient is 0.994 .

3.2. The Wastewater Treatment Process. The treatment conditions were as follows: the volume of wastewater containing $150 \mathrm{mg} / \mathrm{L}$ fuchsine was $50 \mathrm{~mL}, \mathrm{ClO}_{2}$ concentration was $6.14 \mathrm{mg} / \mathrm{L}$, pH value was 5.0, the distance between UV lamp and flask was $20 \mathrm{~cm}$, UV irradiation time was $13 \mathrm{~min}$, and photocatalyst dosage was 0.5 grams. For chemical oxidation, the dosage of photocatalyst was zero. The removal efficiency of fuchsine by UV irradiation chlorine dioxide photocatalytic oxidation could reach $79.88 \%$, comparing with $46.01 \%$ of chlorine dioxide chemical oxidation.

The photocatalytic oxidation process was superior to the chemical oxidation process. The enhancement effect of the photocatalytic oxidation arises mainly from two aspects. The process is initiated upon UV irradiation of the semiconductor with the formation of high-energy electron/hole pairs, and the reaction of the holes with water molecules and hydroxyl ions adsorbed on the surface of $\mathrm{TiO}_{2}$ yields hydroxyl radicals. On the other hand, the resulting hydroxyl radicals, being very strong oxidizing agents, can oxidize the materials of fuchsine into water and carbon dioxide. The strong oxidizer, chlorine dioxide, also acts as an electron

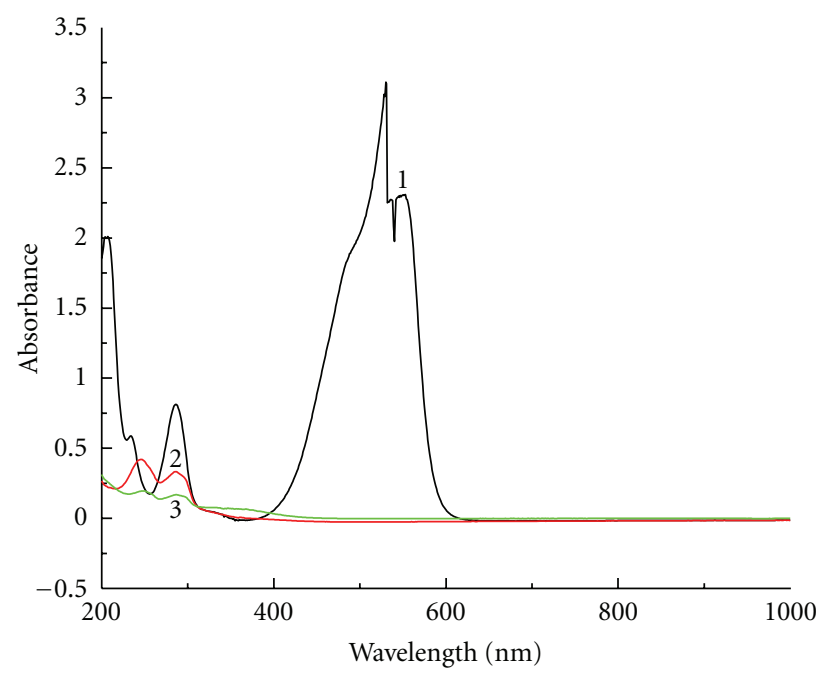

Figure 1: UV-Vis spectra of water samples before and after oxidation (curve 1: simulated wastewater containing fuchsine; curve 2: chemical oxidation; curve 3: photocatalytic oxidation).

acceptor to accept the electron preventing the electron and hole combined together. Therefore, the removal efficiency of fuchsine treated by photocatalytic oxidation process is higher than that of chemical oxidation process.

\subsection{Spectrophotometric Analysis and Characterization}

3.3.1. UV-Vis Spectrophotometric Analysis of Pollutant Changes. In order to study the pollutant changes during the oxidation process, it is necessary to investigate the UV-Vis spectra before and after chlorine dioxide oxidation treatment. Figure 1 represents the UV-Vis spectra of water samples before and after oxidation.

As shown in Figure 1, the simulated wastewater containing fuchsine has a strong absorption peak at $530 \mathrm{~nm}$ (see curve 1), which belongs to the characteristic absorption peak of the longer conjugated pi bonding system of fuchsine molecule. The absorption peak at $530 \mathrm{~nm}$ disappeared after chemical oxidation or photocatalytic oxidation (see curve 2 and 3). It indicates that the longer conjugated pi bonding system of fuchsine molecule can be easily oxidized by chlorine dioxide.

The simulated wastewater containing fuchsine has a strong absorption peak at $285 \mathrm{~nm}$ (see curve 1), which belongs to the characteristic absorption peak of benzene ring. The absorption intensity at $285 \mathrm{~nm}$ decreased after chemical oxidation (see curve 2). We could find that the absorption intensity at $285 \mathrm{~nm}$ further decreased after photocatalytic oxidation (see curve 3 ). This evidence indicated that the simulated wastewater treated by chemical oxidation or photocatalytic oxidation still contained some benzene ring compounds. The chlorine dioxide chemical oxidation or photocatalytic oxidation has the degradative ability to benzene ring compounds to some extent.

By comparing the peak intensity in the UV-Vis spectra of chemical oxidation and photocatalytic oxidation, it indicates 


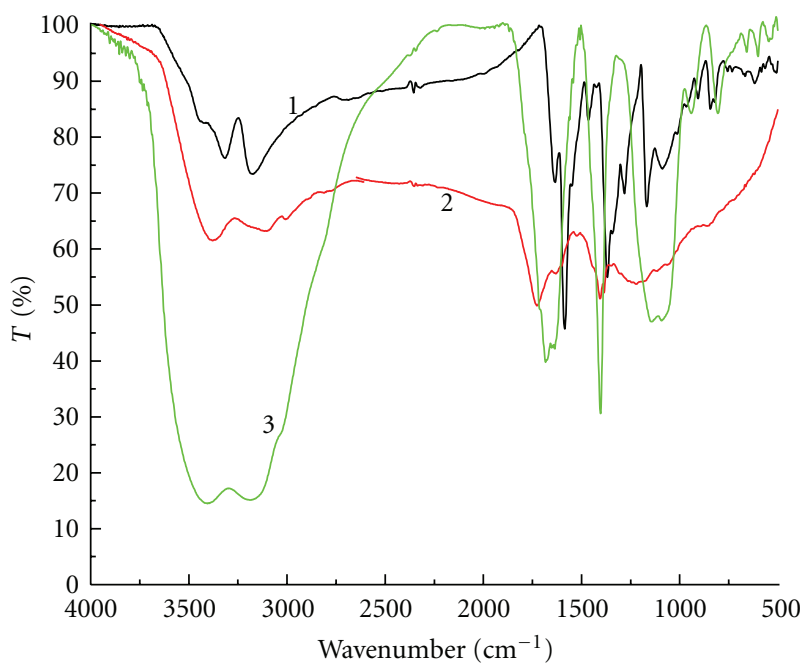

FIGURE 2: The infrared spectrum of fuchsine wastewater before and after oxidation (Curve 1: fuchsine; Curve 2: chemical oxidation; Curve 3: photocatalytic oxidation).

that the extent of removal efficiency by photocatalytic oxidation is greater than that of chemical oxidation.

3.3.2. FTIR Analysis of Pollutant Changes. In order to study the pollutant changes during the oxidation process, the FTIR spectra before and after chlorine dioxide oxidation treatment were further investigated. Figure 2 represents the FTIR spectra of fuchsine samples before and after oxidation.

In the FTIR spectrum of fuchsine (curve 1 in Figure 2), the absorptions near $3317 \mathrm{~cm}^{-1}$ and $3175 \mathrm{~cm}^{-1}$ are assigned to $\mathrm{N}-\mathrm{H}$ stretching vibration of primary amine and $=\mathrm{NH}_{2}^{+} \mathrm{Cl}^{-}$. The absorption near $1633 \mathrm{~cm}^{-1}$ is assigned to $\mathrm{C}=\mathrm{C}$ stretching vibration. The absorptions near $1585 \mathrm{~cm}^{-1}$ and $1460 \mathrm{~cm}^{-1}$ are assigned to benzene ring stretching in aromatic compounds. The absorptions near $1168 \mathrm{~cm}^{-1}$ and $1063 \mathrm{~cm}^{-1}$ are assigned to the $\mathrm{C}-\mathrm{N}$ stretching vibration of aniline in fuchsine.

In the FTIR spectrum of chemical oxidation (Curve 2 in Figure 2), the absorption near $3421 \mathrm{~cm}^{-1}$ is assigned to O$\mathrm{H}$ stretching vibration in carboxylic acids. The absorption near $3145 \mathrm{~cm}^{-1}$ is assigned to $\mathrm{N}-\mathrm{H}$ stretching vibration of primary amine. The absorption near $1523 \mathrm{~cm}^{-1}$ is assigned to benzene ring stretching in aromatic compounds, which indicates that the benzene ring has not been totally oxidized by chlorine dioxide. There is no $\mathrm{C}=\mathrm{O}$ stretching absorption peak in the FTIR spectrum of fuchsine. However, there is a new strong absorption near $1726 \mathrm{~cm}^{-1}$, which is assigned to the $\mathrm{C}=\mathrm{O}$ stretching in carboxylic acids, after treated by chemical oxidation. Also, there is a new absorption near $1631 \mathrm{~cm}^{-1}$, which is assigned to the $\mathrm{C}=\mathrm{O}$ stretching in quinone or conjugated carboxylic acids, after treated by chemical oxidation. That is to say, the benzene ring in fuchsine was degraded into carboxylic acids, quinone, or conjugated carboxylic acids. At the same time, a new absorption near $1406 \mathrm{~cm}^{-1}$, which is assigned to nitrate,

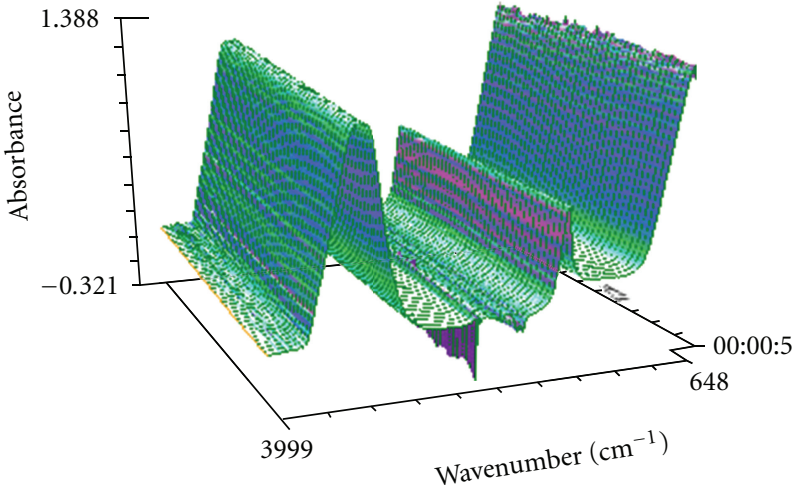

FIGURE 3: The 3D online infrared spectrum of wastewater treatment by chlorine dioxide photocatalytic oxidation process.

appeared. It indicated that the primary amine was oxidized to nitrate by chlorine dioxide.

In the FTIR spectrum of photocatalytic oxidation (Curve 3 in Figure 2), the absorption near $3421 \mathrm{~cm}^{-1}$ is assigned to $\mathrm{O}-\mathrm{H}$ stretching vibration in carboxylic acids. The absorption near $3145 \mathrm{~cm}^{-1}$ is assigned to $\mathrm{N}-\mathrm{H}$ stretching vibration of primary amine. The absorption near $1507 \mathrm{~cm}^{-1}$ is assigned to benzene ring stretching in aromatic compounds, which indicates that the benzene ring has not been totally oxidized by chlorine dioxide. There is no $\mathrm{C}=\mathrm{O}$ stretching absorption peak in the FTIR spectrum of fuchsine. However, there is a new strong absorption near $1683 \mathrm{~cm}^{-1}$, which is assigned to the $\mathrm{C}=\mathrm{O}$ stretching in quinone or conjugated carboxylic acids, after treated by photocatalytic oxidation. That is to say, the benzene ring in fuchsine was degraded into quinone or conjugated carboxylic acids. At the same time, a new absorption near $1403 \mathrm{~cm}^{-1}$, which is assigned to nitrate, appeared. It indicated that the primary amine was oxidized to nitrate by chlorine dioxide.

3.3.3. Online FTIR Analysis of Degradation Mechanism. In order to investigate the mechanism of the chlorine dioxide photocatalytic oxidation, the online FTIR was applied to detect and analyze the products formed during oxidation process. Figure 3 presents the $3 \mathrm{D}$ online infrared spectrum of wastewater treatment by chlorine dioxide photocatalytic oxidation process. The $3 \mathrm{D}$ means absorbance, wavenumber, and reaction time. In Figure 3, the strong absorptions near $3315 \mathrm{~cm}^{-1}$ and $1636 \mathrm{~cm}^{-1}$ are assigned to the $\mathrm{O}-\mathrm{H}$ stretching of water and the $\mathrm{H}-\mathrm{O}-\mathrm{H}$ bending of water, respectively.

Two intermediates were detected automatically during the online FTIR analysis. Its FTIR spectra were obtained. In the FTIR spectrum of intermediate 1 (Figure 4), the absorption near $1107 \mathrm{~cm}^{-1}$ is assigned to the $\mathrm{O}-\mathrm{H}$ inplane deformation in carboxylic acids. The absorption near $1748 \mathrm{~cm}^{-1}$ is assigned to the $\mathrm{C}=\mathrm{O}$ stretching in carboxylic acids, which should be the product of ethanedioic acid in the degradation reaction mechanism. The absorption near $1652 \mathrm{~cm}^{-1}$ is assigned to the $\mathrm{C}=\mathrm{O}$ stretching in $p$-quinone or carboxylic acids, which is conjugated with $\mathrm{C}=\mathrm{C}$ double bond. It should be the product of $p$-quinone or butenedioic acid in 


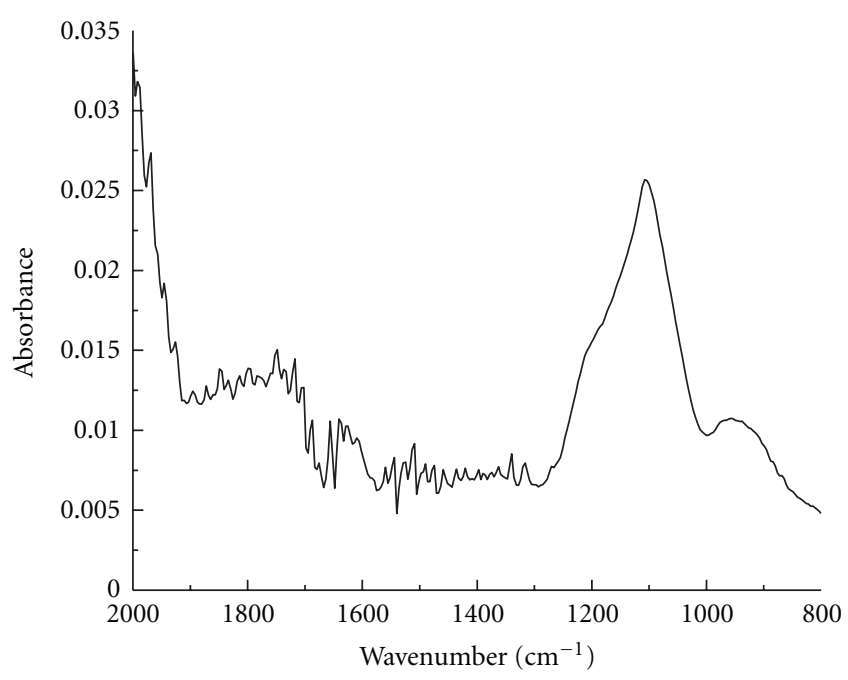

FIgURE 4: The infrared spectrum of intermediate 1.

the degradation reaction mechanism. The absorptions near $1546 \mathrm{~cm}^{-1}, 1519 \mathrm{~cm}^{-1}$, and $1509 \mathrm{~cm}^{-1}$ are assigned to the $\mathrm{C}=\mathrm{C}$ stretching in ethylene, which is conjugated with $\mathrm{C}=\mathrm{O}$ bond. It should be the product of $p$-quinone or butenedioic acid in the degradation reaction mechanism. Therefore, intermediate 1 should be one of the $p$-quinone, butenedioic acid, or ethanedioic acid.

In the FTIR spectrum of intermediate 2 (the figure is omitted), the absorption near $1605 \mathrm{~cm}^{-1}$ is assigned to the $\mathrm{C}=\mathrm{O}$ stretching in $p$-quinone or carboxylic acids, which is conjugated with $\mathrm{C}=\mathrm{C}$ double bond. It should be the product of $p$-quinone or butenedioic acid in the degradation reaction mechanism. Therefore, intermediate 2 should be one of the p-quinone or butenedioic acid.

Figure 5 gives the intermediate 1 relative concentration (c) versus reaction time. Figure 6 gives the intermediate 2 relative concentration versus reaction time. As shown in Figures 5-6, the relative concentrations of intermediates 1 and 2 increase with reaction time. Therefore, intermediate 1 should be one of the p-quinone, butenedioic acid, or ethanedioic acid. Intermediate 2 should be one of the $p$ quinone or butenedioic acid.

3.4. The Mechanism of Chlorine Dioxide Photocatalytic Oxidation of Fuchsine. Fuchsine was oxidized by chlorine dioxide and hydroxyl radical into $p$-quinone and carboxylic acids during the photocatalytic oxidation process. Finally, it was changed into carbon dioxide and water. Therefore, the degradation reaction mechanism of fuchsine by chlorine dioxide and hydroxyl radical oxidation was proposed based upon the experiment evidence. The mechanism was presented in Figure 7.

\section{Conclusions}

(1) The chlorine dioxide photocatalytic oxidation process is an interesting technique for the treatment of wastewater. The removal efficiency of fuchsine

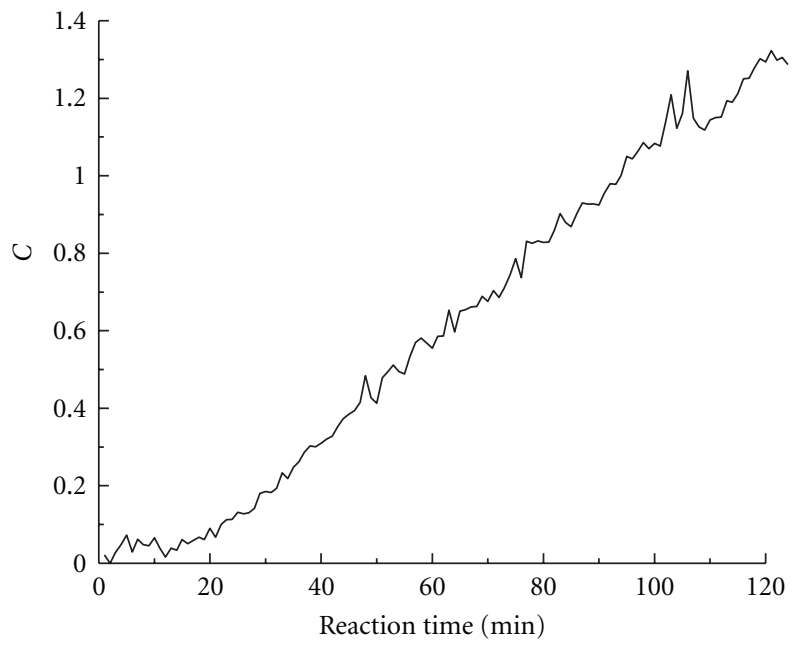

Figure 5: The curve of the intermediate 1 relative concentration versus reaction time.

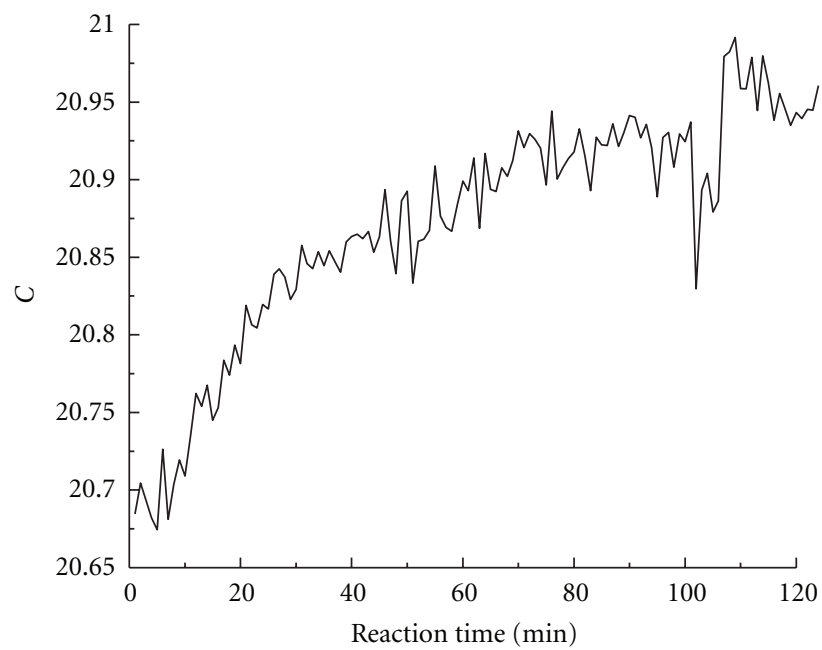

Figure 6: The curve of the intermediate 2 relative concentration versus reaction time.

treated by photocatalytic oxidation process is higher than that of chemical oxidation process. It may have great practical significance for the design of actual wastewater treatment process.

(2) The research on the degradation mechanism showed that the UV irradiation could induce the titanium dioxide to generate an electron-hole $\left(\mathrm{e}^{-} / \mathrm{h}^{+}\right)$, where the $\mathrm{h}^{+}$oxidizes strongly $\mathrm{OH}^{-}$and $\mathrm{H}_{2} \mathrm{O}$ to produce hydroxyl radical $\left(\mathrm{HO}^{\circ}\right)$, and the $\mathrm{e}^{-}$combines with $\mathrm{O}_{2}$ to form superoxide ion $\left(\mathrm{O}_{2}{ }^{-}\right)$. The stronger oxidant of $\mathrm{HO}^{-}$and $\mathrm{O}_{2}{ }^{-}$oxidizes fuchsine to produce quinone and carboxylic acids during the oxidation process. In the end, it was degraded into water and carbon dioxide. Moreover, the strong oxidizer chlorine dioxide was not only used to oxidize fuchsine, but also used as the electron acceptor, which could inhibit electron-hole pair recombination 


$$
\begin{gathered}
\mathrm{TiO}_{2}+h v(\mathrm{UV}) \longrightarrow \mathrm{TiO}_{2}\left(\mathrm{e}_{\mathrm{CB}}^{-}+\mathrm{h}_{\mathrm{VB}}{ }^{+}\right) \\
\mathrm{TiO}_{2}\left(\mathrm{~h}_{\mathrm{VB}}{ }^{+}\right)+\mathrm{H}_{2} \mathrm{O} \longrightarrow \mathrm{TiO}_{2}+\mathrm{H}^{+}+\mathrm{HO} \cdot \\
\mathrm{TiO}_{2}\left(\mathrm{~h}_{\mathrm{VB}}{ }^{+}\right)+\mathrm{OH}^{-} \longrightarrow \mathrm{TiO}_{2}+\mathrm{HO} \cdot \\
\mathrm{TiO}_{2}\left(\mathrm{e}_{\mathrm{CB}}^{-}\right)+\mathrm{O}_{2} \longrightarrow \mathrm{TiO}_{2}+\mathrm{O}_{2}^{-} \\
\mathrm{O}_{2}^{-} \cdot+\mathrm{H}^{+} \longrightarrow \mathrm{HO}_{2}^{\cdot} \\
5 \mathrm{TiO}_{2}\left(\mathrm{e}_{\mathrm{CB}}^{-}\right)+\mathrm{ClO}_{2}+4 \mathrm{H}^{+} \longrightarrow 5 \mathrm{TiO}_{2}+\mathrm{Cl}^{-}+2 \mathrm{H}_{2} \mathrm{O}
\end{gathered}
$$<smiles></smiles>

(a)

(b)<smiles>Cc1cc(C(=O)c2ccc(N)cc2)ccc1N</smiles><smiles>O=C1C=CC(=O)C=C1</smiles><smiles>CC1=CC(=O)C=CC1=O</smiles><smiles>O=C1C=CC(=O)C1</smiles>

(c)

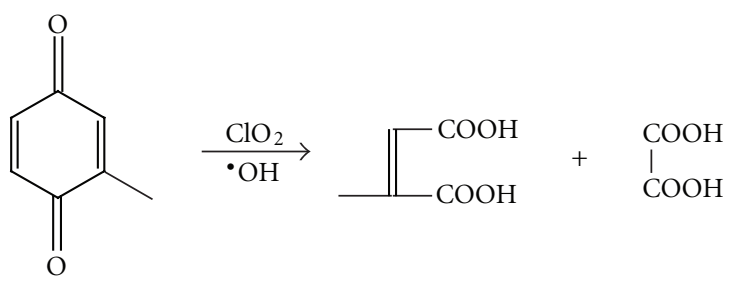

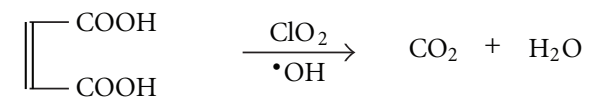

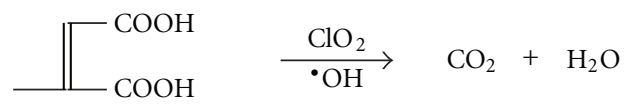

$$
\underset{\mathrm{COOH}}{\stackrel{\mathrm{COOH}}{\mathrm{ClO}_{2}}} \stackrel{\mathrm{CO}_{2}}{\stackrel{\mathrm{OH}}{\longrightarrow}} \mathrm{H}_{2} \mathrm{O}
$$

Figure 7: The degradation reaction mechanism of fuchsine. 
to enhance the degradation rate. The result may have great importance for the theoretical study of wastewater treatment.

(3) By using UV-Vis and online FTIR analysis technique, the intermediates during the degradation process were obtained. It was useful to investigate the degradation reaction mechanism of the pollutants. The result may have important theoretical significance.

\section{Acknowledgments}

The authors would like to thank the financial support from the Shandong Provincial Natural Science Foundation (no. ZR2009BM007) and the Scientific Research Foundation for the Returned Overseas Chinese Scholars, State Education Ministry, China.

\section{References}

[1] M. A. Shannon, P. W. Bohn, M. Elimelech, J. G. Georgiadis, B. J. Marinas, and A. M. Mayes, "Science and technology for water purification in the coming decades," Nature, vol. 452, no. 7185, pp. 301-310, 2008.

[2] F. Tian, Z. Qiang, C. Liu, T. Zhang, and B. Dong, "Kinetics and mechanism for methiocarb degradation by chlorine dioxide in aqueous solution," Chemosphere, vol. 79, no. 6, pp. 646-651, 2010.

[3] S. Y. Kim, J. Y. An, and B. W. Kim, "The effects of reductant and carbon source on the microbial decolorization of azo dyes in an anaerobic sludge process," Dyes and Pigments, vol. 76, no. 1, pp. 256-263, 2008.

[4] M. Pandurangachar, B. E. Kumara Swamy, B. N. Chandrashekar, O. Gilbert, and B. S. Sherigara, "Electrochemical deposition of 1-butyl-4-methyl-pyridinium tetrafluroborate ionic liquid on carbon paste electrode and its application for the simultaneous determination of dopamine, ascorbic acid and uric acid," Journal of Molecular Liquids, vol. 158, no. 1, pp. 13-17, 2011.

[5] L. Shi, N. Li, C. Wang, and C. Wang, "Catalytic oxidation and spectroscopic analysis of simulated wastewater containing ochlorophenol by using chlorine dioxide as oxidant," Journal of Hazardous Materials, vol. 178, no. 1-3, pp. 1137-1140, 2010.

[6] F. Yu and L. Shi, "Catalytic oxidation and spectroscopic analysis of simulated wastewater containing acid chrome blue $\mathrm{K}$ by using chlorine dioxide as oxidant," Water Science and Technology, vol. 61, no. 8, pp. 1931-1940, 2010.

[7] T. Z. Péerez, G. Geissler, and F. Hernandez, "Chemical oxygen demand reduction in coffee wastewater through chemical flocculation and advanced oxidation processes," Journal of Environmental Sciences, vol. 19, no. 3, pp. 300-305, 2007.

[8] O. Legrini, E. Oliveros, and A. M. Braun, "Photochemical processes for water treatment," Chemical Reviews, vol. 93, no. 2, pp. 671-698, 1993.

[9] C. S. Turchi and D. F. Ollis, "Photocatalytic degradation of organic water contaminants: mechanisms involving hydroxyl radical attack," Journal of Catalysis, vol. 122, no. 1, pp. 178192, 1990.

[10] M. Abu Tariq, M. Faisal, M. Saquib, and M. Muneer, "Heterogeneous photocatalytic degradation of an anthraquinone and a triphenylmethane dye derivative in aqueous suspensions of semiconductor," Dyes and Pigments, vol. 76, no. 2, pp. 358365, 2008.

[11] A. V. Vorontsov and V. P. Dubovitskaya, "Selectivity of photocatalytic oxidation of gaseous ethanol over pure and modified $\mathrm{TiO}_{2}$," Journal of Catalysis, vol. 221, no. 1, pp. 102109, 2004.

[12] J. B. de Heredia, J. Torregrosa, J. R. Dominguez, and J. A. Peres, "Oxidation of p-hydroxybenzoic acid by UV radiation and by $\mathrm{TiO}_{2} / \mathrm{UV}$ radiation: comparison and modelling of reaction kinetic," Journal of Hazardous Materials, vol. 83, no. 3, pp. 255264, 2001.

[13] M. Saquib and M. Muneer, "Titanium dioxide mediated photocatalyzed degradation of a textile dye derivative, acid orange 8 , in aqueous suspensions," Desalination, vol. 155, no. 3, pp. 255-263, 2003.

[14] G. A. Epling and C. Lin, "Photoassisted bleaching of dyes utilizing $\mathrm{TiO}_{2}$ and visible light," Chemosphere, vol. 46, no. 4, pp. 561-570, 2002.

[15] C. Bauer, P. Jacques, and A. Kalt, "Photooxidation of an azo dye induced by visible light incident on the surface of $\mathrm{TiO}_{2}$," Journal of Photochemistry and Photobiology A, vol. 140, no. 1, pp. 87-92, 2001.

[16] R. W. Matthews and S. R. McEvoy, "Photocatalytic degradation of phenol in the presence of near-UV illuminated titanium dioxide," Journal of Photochemistry and Photobiology A, vol. 64, no. 2, pp. 231-246, 1992.

[17] A. Y. Shan, T. I. M. Ghazi, and S. A. Rashid, "Immobilisation of titanium dioxide onto supporting materials in heterogeneous photocatalysis: a review," Applied Catalysis A, vol. 389, no. 1-2, pp. 1-8, 2010.

[18] B. Neppolian, H. C. Choi, S. Sakthivel, B. Arabindoo, and V. Murugesan, "Solar light induced and $\mathrm{TiO}_{2}$ assisted degradation of textile dye reactive blue 4," Chemosphere, vol. 46, no. 8 , pp. 1173-1181, 2002.

[19] C. Hu, L. Y. Lin, and X. X. Hu, "Morphology of metal nanoparticles photodeposited on $\mathrm{TiO}_{2} /$ silical gel and photothermal activity for destruction of ethylene," Journal of Environmental Sciences, vol. 18, no. 1, pp. 76-82, 2006. 


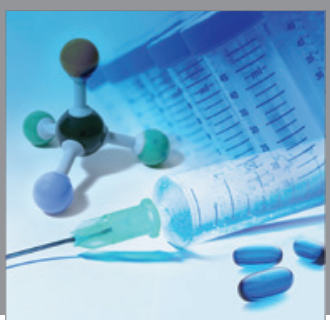

International Journal of

Medicinal Chemistry

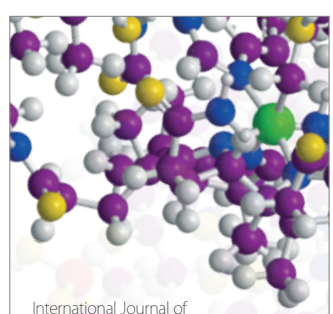

Carbohydrate Chemistry

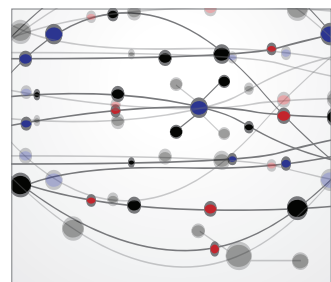

The Scientific World Journal
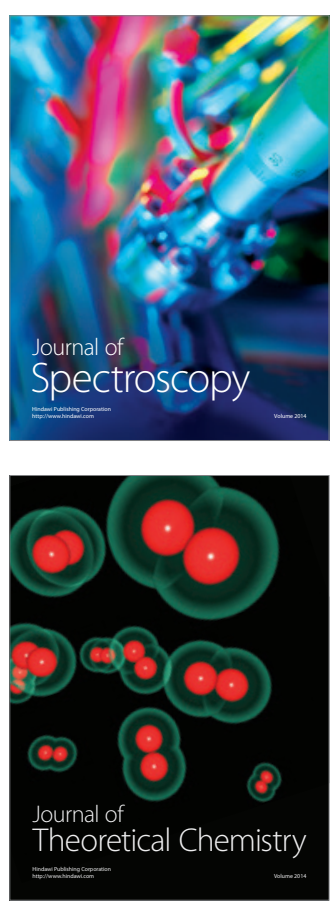
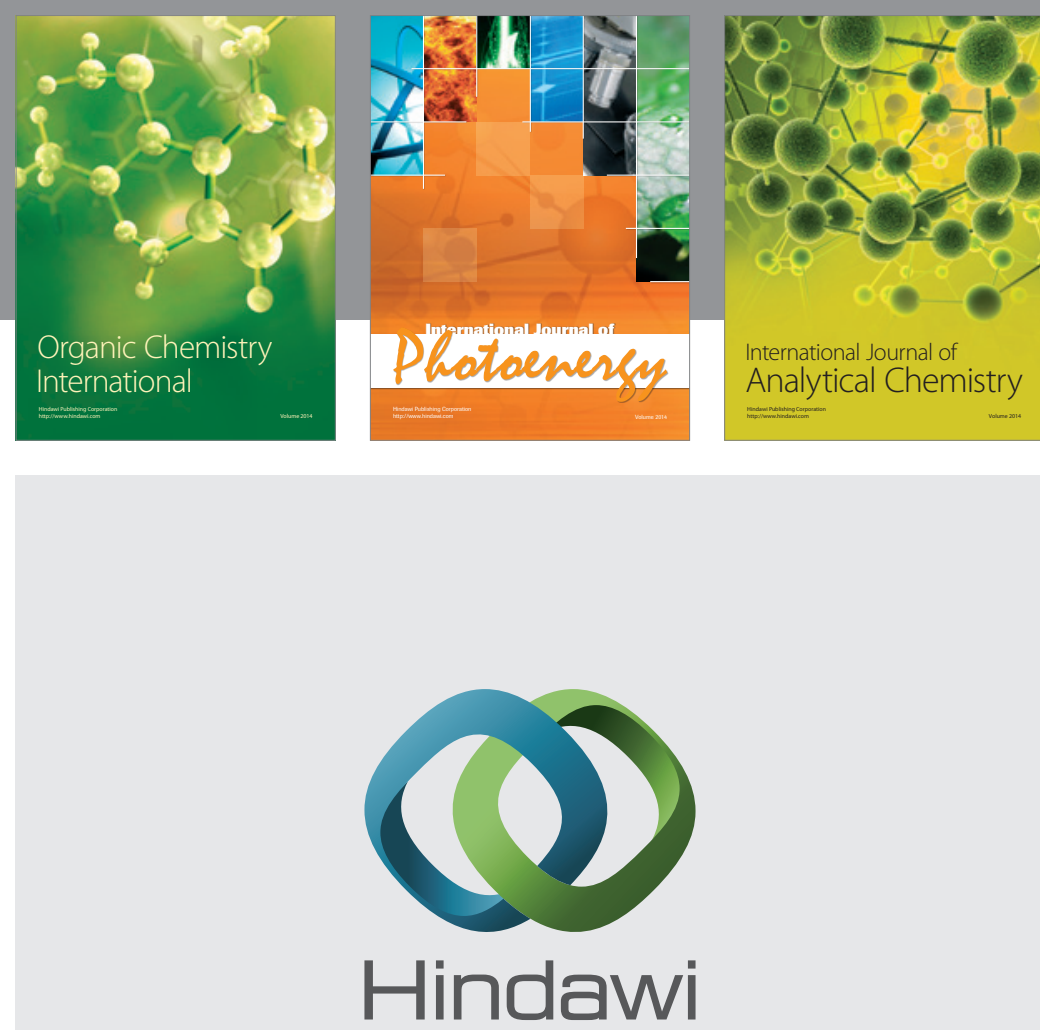

Submit your manuscripts at

http://www.hindawi.com
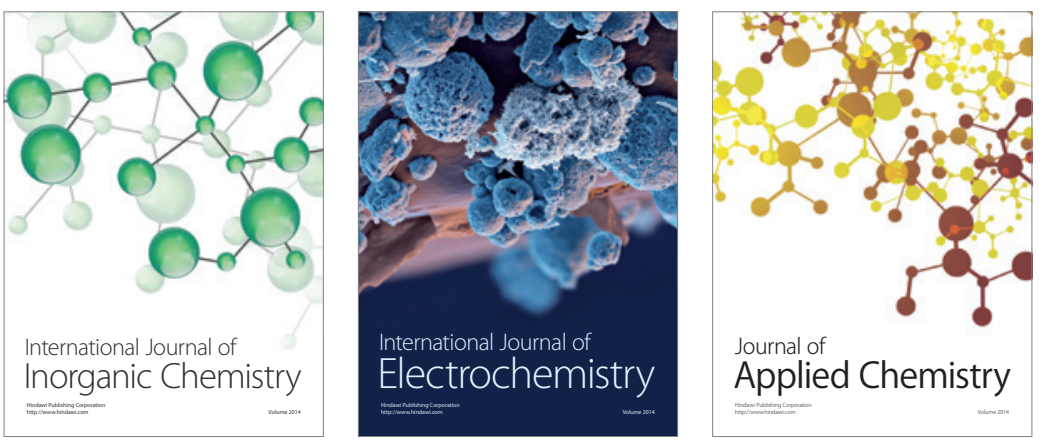

Journal of

Applied Chemistry
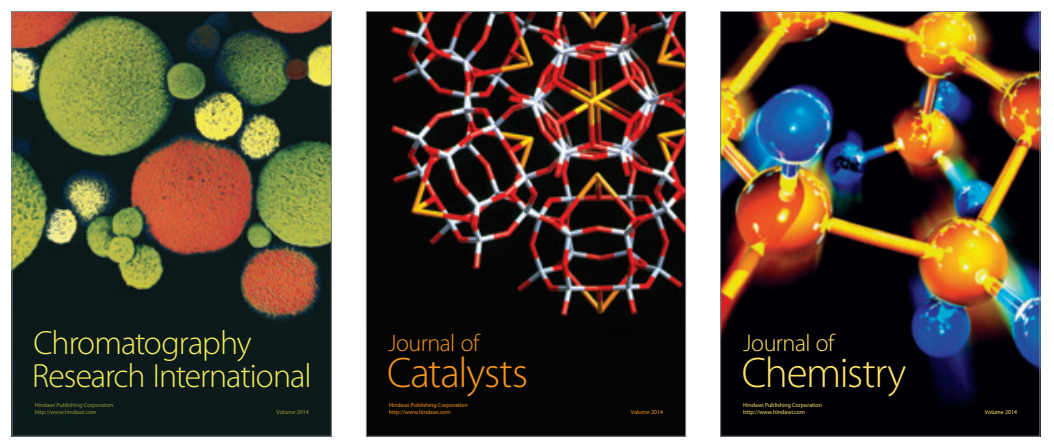
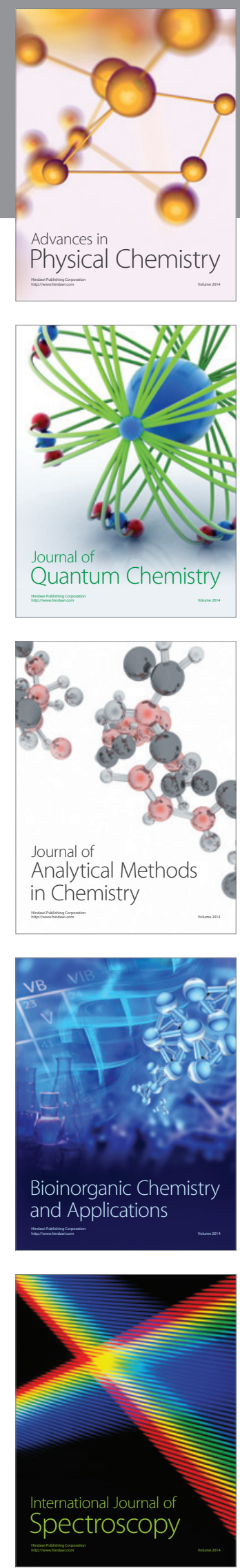